\title{
BOTTOM NEPHELOID LAYER
}

\section{BY YOGESH AGRAWAL}

Quite like the dust layer that establishes itself over land under a strong wind, a particle-rich nepheloid layer typically exists on the ocean floor. The dynamics of this layer constitute the area of research called bottom boundary layers and sediment transport.

The nepheloid layer has the following four basic properties: (1) the layer has a thickness that scales with the vigor of the currents on the bottom, $k u_{*} / f$; where $k$ is about $0.41, u_{*}$ is the bottom friction velocity $(=\sqrt{ } \tau / \rho, \tau$ being bottom frictional stress and $\rho$ being water density), and $f$ is the Coriolis parameter,

(2) the water in the layer is typically most turbid at the greatest depth and clears further from the boundary, (3) the layer is sustained by a balance between gravitational settling and turbulent vertical diffusion counteracting it, and (4) there exists a vertical gradient in the concentration of particles of any given size, with the gradient being strongest for the fastest settling particles. In addition to these four basic properties, the dynamics of the bottom nepheloid layer are characterized by the stripping of sediment off the seafloor due to frictional stress of water motions so that the availability of sediment at the bed may determine the bottom boundary condition for sediments. Whereas all of these properties are similar to common atmospheric experience, waves introduce an additional phenomenon on the seafloor that has no counterpart in the atmosphere. Surface gravity waves induce oscillatory motions on the seabed. This motion, in turn has its own, typically much thinner boundary layer-a wave boundary layer-that is capable of suspending more bed material than an equally strong current. As a result, a combination of waves and currents can suspend a large amount of material. The suspended material increases the beam attenuation coefficient $c$. Conversely, the absence of bottom water motion permits the sediment to fall out of suspension, clearing the water column. Observations in the nepheloid layer have been made quite extensively. These reveal a wide dynamic range of changes in the amount of sediment carried in the nepheloid layer.

From the standpoint of optics, the nepheloid layer complicates bathymetry. For example, the suspended particles reflect light from a LIDAR pulse, which stretches a bottom return. Furthermore, as light propagates into the nepheloid layer it is absorbed, so that a weaker laser pulse reaches the bottom. The bottom-reflected energy is again attenuated as it propagates through the nepheloid layer up toward the surface. This two-way attenuation depends on the beam attenuation coefficient $c$ and the boundary layer thickness. Given typical order of magnitude values for $c\left[\sim 1-30 \mathrm{~m}^{-1}\right]$ and boundary layer thickness $\delta$ of order $10 \mathrm{~m}$, it is readily apparent that the round-trip attenuation of a laser pulse can reach $\exp (-10)$ or more. Thus the presence of a

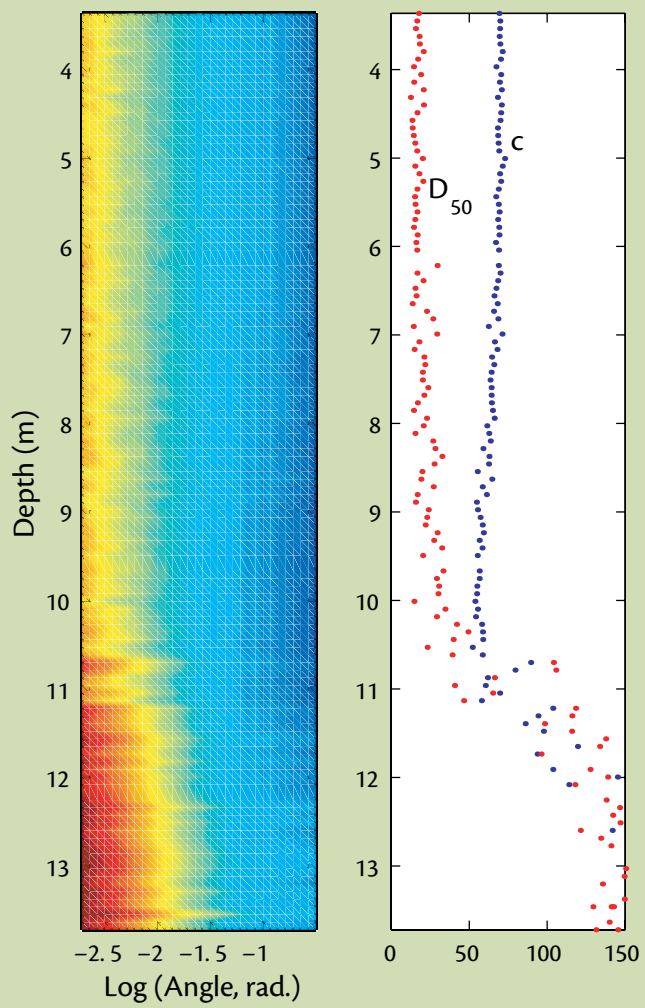

bottom nepheloid layer can dramatically influence the visibility of the bottom from above, restricting LIDAR bathymetry.

In addition to the bottom resuspension mechanism described above, other more complex processes determine the overall water column properties. For example, upwelling events can act as conveyor belts, carrying to the surface sediment that was originally present in the nepheloid layer. In such cases, a bottom and surface nepheloid layer can exist. A surface wind stress may produce thickening of the surface layer, leading to interaction of the two, and establishment of a more complex columnar turbidity structure. Needless to say, given all the factors that determine the overall properties of a water column, continuing research in the underlying processes is vital to improving our quantitative understanding. 四
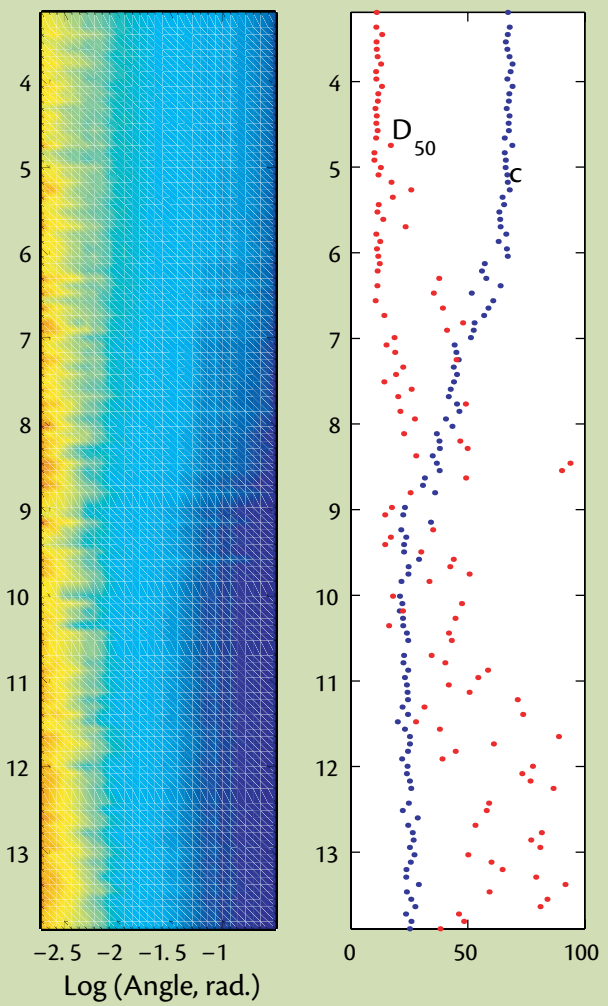

Two pairs of figures illustrate a case of an existing bottom turbid layer (left) versus a surface turbid layer (right) presumably due to an upwelling event. The left panel in each pair is the volume scattering function, plotted against depth on the ordinate. The right panel of each pair is a vertical profile of the beam-c (attenuation) [magnified by 20x] and the mean sediment grain diameter in microns. In the turbid bottom layer case, it is the classic behavior of larger grains and larger attenuation hugging the bottom. The turbid surface layer is quite different: the beam-c is higher near surface. The volume scattering function (VSF) is weaker and less steep, and the grain size is larger though more scattered in the lower half, despite lower beam-c; all these characteristics are probably due to the presence of marine flocs. 